\title{
Avaliação do efeito de enxaguatórios bucais na rugosidade superficial de resinas acrílicas quimicamente ativadas
}

\section{Evaluation of oral mouth rinses in superficial roughness of self-curing acrylic resin}

\author{
Hanna Larissa FAGUNDES \\ Cirurgiã-Dentista.
}

\section{Roselaine POZZOBON}

Professora Doutora - Departamento de Odontologia Restauradora - Universidade Federal de Santa Maria - UFSM - RS - Brasil.

\section{Letícia Borges JACQUES}

Professora Doutora - Departamento de Odontologia Restauradora - Universidade Federal de Santa Maria - UFSM - Santa Maria-RS- Brasil.

\author{
André MALLMANN \\ Professor Doutor - Departamento de Estomatologia - Universidade Federal de Santa Maria - UFSM - RS - Brasil.
}

\begin{abstract}
Resumo
O objetivo neste trabalho foi avaliar o efeito de dois enxaguatórios bucais (Periogard [PER] (Colgate-Palmolive Ind. Com. Ltda - São Paulo, SP, Brasil) e Listerine [LIS] (Johnson \& Johnson Healthcare Products - Skillman-NJ,EUA)) na rugosidade de superficie de duas resinas acrílicas polimerizáveis quimicamente (Duralay [DUR] (Reliance Dental Worth, IL, EUA] e Dencrilay [DEN] (Dencril Caieiras, SP, Brasil)), tendo como grupo controle o soro fisiológico [SOR], totalizando 6 grupos $(n=8)$. Para a confecção dos corpos-de-prova $(\mathrm{CP})$ foram utilizadas 48 matrizes de poliacetal com um orifício central cilíndrico de $5 \mathrm{~mm}$ de diâmetro por $5 \mathrm{~mm}$ de profundidade. A resina acrílica foi manipulada e inserida no orifício com seringa plástica, com a matriz posicionada sobre uma lâmina de vidro. Outra lâmina foi pressionada sobre a matriz e esse conjunto foi colocado numa panela de pressão durante a polimerização. As faces correspondentes aos diâmetros dos cp foram regularizadas com lixa d'água 220 e as faces que apresentaram menos irregularidades receberam o acabamento com as demais lixas $(320,400,600,1200)$ sob refrigeração com água, em uma politriz. Após 24 horas de armazenagem em água foram realizadas as leituras iniciais num rugosímetro na escala Ra. Os CP foram imersos nas soluções para bochecho durante 10 minutos por dia, por 10 dias. Entre os intervalos de imersão nas soluções para bochechos as resinas ficaram armazenados em soro fisiológico. Nesse período, o grupo controle ficou todo o tempo armazenado em soro fisiológico. Em seguida, os $\mathrm{CP}$ foram submetidos à leitura final de rugosidade (Ra), pelo mesmo avaliador. Os resultados iniciais foram: $\mathrm{DUR}+\mathrm{LIS}=0,20 ; \mathrm{DUR}+\mathrm{PER}=0,21 ; \mathrm{DUR}+\mathrm{SOR}=0,25 ; \mathrm{DEN}+\mathrm{LIS}=0,33$; $\mathrm{DEN}+\mathrm{SOR}=0,33 ; \mathrm{DEN}+\mathrm{PER}=0,36$; e finais: $\mathrm{DUR}+\mathrm{PER}=0,28 ; \mathrm{DUR}+\mathrm{LIS}=0,28 ; \mathrm{DEN}+\mathrm{SOR}=0,31 ; \mathrm{DUR}+\mathrm{SOR}=0,34$; $\mathrm{DEN}+\mathrm{PER}=0,43 ; \mathrm{DEN}+\mathrm{LIS}=0,43$. A análise de variância e o teste de Tukey (5\%) mostraram que a resina acrílica Duralay apresentou menor rugosidade de superfície e as soluções aumentaram significantemente as suas rugosidades com o tempo. Não houve diferença significante entre as soluções testadas.
\end{abstract}

\section{UNITERMOS}

Resinas acrílicas; agentes antissépticos; rugosidade.

\section{INTRODUÇÃO}

As restaurações provisórias constituem uma etapa importante na execução da prótese fixa, pois nesta etapa podem se avaliar a condição pulpar e periodontal, além dos aspectos fonéticos, estético e auto-estima do paciente.

Muitas vezes passam várias semanas ou meses entre o preparo dos dentes e a cimentação definitiva. É 
importante obter acabamento e polimento adequado da restauração provisória, a fim de promover superfícies lisas e polidas, na tentativa de reduzir o acúmulo de placa bacteriana e, conseqüentemente, a ocorrência de doenças como cárie e as relacionadas ao tecido periodontal, pela facilidade de higienização ${ }^{13}$. Os materiais mais utilizados para este fim são as resinas acrílicas quimicamente ativadas, devido à facilidade de uso, menor custo e propriedades físicas e mecânicas satisfatórias.

A rugosidade de superfície das restaurações provisórias apresenta grande importância clínica em relação à retenção de placa bacteriana, por isso a necessidade de se obter uma superfície mais polida ${ }^{2}$. Nikawa et a ${ }^{12}$ salientam que a formação de placa bacteriana na superfície das restaurações provisórias é semelhante à placa bacteriana dental e o seu controle é igualmente importante.

Diferentes marcas de resinas acrílicas quimicamente ativadas utilizadas para confecção de restaurações protéticas temporárias são encontradas na Odontologia, podendo apresentar diferentes rugosidades superficiais ${ }^{3}$. Vários aspectos podem ser relacionados a esta rugosidade, sugere-se que o tipo e tamanho de partículas de seus polímeros, o polimento empregado, a solubilidade e degradação superficial da resina quando expostas ao meio bucal provavelmente são fatores relevantes.

Em muitas situações, durante o tratamento periodontal, principalmente nos períodos pós-cirúrgicos, os pacientes utilizam enxaguatórios bucais como coadjuvantes no controle de placa bacteriana ${ }^{9}$. A clorexidina é o agente bucal antimicrobiano mais utilizado na Odontologia, na forma de sal digluconato, que segundo Egelberg ${ }^{7}$ parece ser eficaz o suficiente para a substituição adequada do controle mecânico da placa por um curto período de tempo, principalmente pelo seu comprovado efeito antimicrobiano 10,5,4. Outro enxaguatório bucal antimicrobiano muito utilizado é o Listerine ${ }^{\circledR}$, que é a base de óleo essencial e também ajuda a prevenir e reduzir o acúmulo de placa supragengival e gengivite quando utilizado num consciente programa de higiene bucal e cuidado profissional regular ${ }^{16}$. Bollen et al. ${ }^{1}$ publicaram uma revisão de literatura sobre a rugosidade de superfície inicial de vários materiais, bem como as mudanças na rugosidade como conseqüência de diversas modalidades de tratamento. De acordo com os autores, algumas pesquisas in vivo sugeriram um limiar de rugosidade para a retenção de placa bacteriana $(\mathrm{Ra}=0,2 \mu \mathrm{m})$ abaixo do qual nenhuma redução no acúmulo de bactérias pode ser esperada. Um aumento da rugosidade acima deste limiar, entretanto, resultou em simultâneo aumento no acúmulo de placa, o que poderia aumentar o risco de lesões de cárie e inflamação periodontal.

Muitos dos colutórios bucais apresentam solventes orgânicos na composição que podem alterar a dureza e a rugosidade das resinas acrílicas, principalmente quando em contato por períodos prolongados. Neppelenbroek et $a l^{11}$ verificaram que houve diferença significativa na dureza de superfície de duas resinas acrílicas termicamente ativadas, quando submetidas a desinfecção com Perborato de Sódio 3,78\%, Digluconato de Clorexidina 4\% e Hipoclorito de Sódio 1\% em diferentes tempos.

No entanto, observa-se que a literatura ainda não é clara no que se refere ao efeito dos colutórios sobre as resinas acrílicas e poucos trabalhos são relatados confirmando ou não o aumento da rugosidade quando submetidas a bochechos com colutórios bucais, principalmente as resinas acrílicas ativadas quimicamente.

O objetivo neste trabalho foi avaliar o efeito de dois enxaguatórios bucais na rugosidade superficial de duas resinas acrílicas polimerizadas quimicamente usadas para a confecção de restaurações provisórias em Prótese Parcial Fixa.

A hipótese a ser testada é que as resinas acrílicas apresentarão rugosidades de superfície diferentes e que os enxaguatórios bucais terão diferentes efeitos sobre a rugosidade destas resinas acrílicas.

\section{Material e Métodos}

Para o desenvolvimento desse estudo foram selecionadas duas resinas acrílicas quimicamente ativadas e dois enxaguatórios bucais, tendo o soro fisiológico como controle. O nome comercial, composição e fabricante dos materiais estão listados no Quadro 1. 
Quadro 1 - Nome, composição e fabricantes dos materiais utilizados

\begin{tabular}{|c|c|c|c|}
\hline Materiais & $\begin{array}{l}\text { Nome } \\
\text { Comercial }\end{array}$ & Composição & Fabricante \\
\hline \multirow{2}{*}{$\begin{array}{l}\text { Resinas acrílicas } \\
\text { ativadas } \\
\text { quimicamente }\end{array}$} & $\begin{array}{l}\text { Duralay } \\
\text { [DUR] }\end{array}$ & $\begin{array}{l}\text { Co-polímero de metil-metacrilato, pigmentos, } \\
\text { aditivos }\end{array}$ & $\begin{array}{l}\text { Reliance } \\
\text { Dental }\end{array}$ \\
\hline & $\begin{array}{l}\text { Dencrilay } \\
\text { Speed [DEN] }\end{array}$ & $\begin{array}{l}\text { Metil metacrilato, acrilato de butila, peróxido } \\
\text { de benzoíla, etileno glicol, pigmentos } \\
\text { orgânicos }\end{array}$ & Dencril \\
\hline \multirow[t]{2}{*}{ Enxaguatórios bucais } & $\begin{array}{l}\text { PerioGard } \\
\text { [PER] }\end{array}$ & $\begin{array}{l}\text { Gluconato de clorexidina a } 0,12 \% \text {, glicerina, } \\
\text { etanol, polisorbato } 20 \text {, sacarinato de sódio, } \\
\text { composição aromática } \\
\text { FD\&C blue } n^{\circ} 1\end{array}$ & Colgate \\
\hline & $\begin{array}{l}\text { Listerine } \\
\text { [LIS] }\end{array}$ & Timol, mentol, eucaliptol, salicilato de metila & Pfizer \\
\hline Soro fisiológico [SOR] & $\begin{array}{l}\text { Soro } \\
\text { Fisiológico }\end{array}$ & Solução de cloreto de sódio a 0,9\% & LBS \\
\hline
\end{tabular}

\section{Confecção dos corpos-de-prova}

Quarenta e oito matrizes em poliacetal com 5,0 mm de espessura e perfuração central cilíndrico de $5,0 \mathrm{~mm}$ de diâmetro foram utilizadas para a confecção dos corpos-de-prova (CP), os quais foram divididos em 6 grupos $(\mathrm{n}=08)$ conforme o delineamento experimental, interagindo as resinas acrílicas (Duralay [Reliance Dental - Worth, IL, EUA] e Dencrilay [Dencril Caieiras - SP Brasil]) com as soluções (soro fisiológico, Listerine [Johnson \& Johnson Healthcare Products Skillman-NJ, EUA] e Periogard [Colgate-Palmolive Ind. Com. Ltda - São Paulo - SP, Brasil]).

Cada matriz foi disposta sobre uma lâmina de vidro, as resinas acrílicas foram proporcionadas e manipuladas de acordo com as instruções dos fabricantes e inseridas na perfuração central das matrizes com seringa plástica descartável. Outra lâmina de vidro foi pressionada sobre a matriz e o conjunto foi preso com um elástico. Este conjunto foi imediatamente colocado em panela de pressão com água durante a sua polimerização das resinas, visando reduzir as bolhas de ar. Após 15 minutos, as faces superior e inferior dos $\mathrm{CP}$ foram regularizadas com lixa d'água de granulação 220 sob refrigeração com água utilizando politriz (Arotec - Modelo APL 4; São Paulo - SP, Brasil). Com o auxílio de lupa com $4 \mathrm{x}$ de aumento (BioArt, São Carlos, SP, Brasil) os CP foram inspecionados e a face que apresentou menos irregularidade superficial recebeu o acabamento com as demais lixas em série decrescente de granulação: 320, 400, 600 e 1200 , sob refrigeração com água e durante 30 segundos em cada lixa. Os CP foram lavados abundantemente por 1 minuto em água corrente entre as trocas de inicial ficaram $24 \mathrm{~h}$ imersos em água em temperatura ambiente (aproximadamente entre 23 e $27^{\circ} \mathrm{C}$ ).

\section{Mensuração da rugosidade superficial}

Após a calibragem do rugosímetro, (Mitutoyo SJ201, Tokio, Japão), na escala Ra, foram realizadas 10 leituras para cada CP, 5 em cada um dos eixos x e y, de modo a determinar a rugosidade superficial inicial. Todos os cp foram numerados para a comparação com a segunda leitura.

Os CP foram imersos nas respectivas soluções para bochecho durante 10 minutos por dia, por um período de 10 dias. As soluções foram renovadas todos os dias e a cada troca os CP foram lavados em água corrente e mantidos em soro fisiológico. O grupo controle ficou todo o tempo armazenado em soro fisiológico.

Após este período, os CP foram submetidos a nova leitura da rugosidade superficial na escala Ra conforme descrito anteriormente, pelo mesmo avaliador. A média dos valores de rugosidade inicial e final foi calculada para cada $\mathrm{CP}$ e também a média do grupo para cada condição experimental. Os dados obtidos foram analisados estatisticamente utilizando o teste de análise de variância e teste de Tukey (5\%). 


\section{Resultados}

Nas Tabelas 1 e 2 são apresentadas, respectivamente, a análise de variância e as médias de rugosidades superficiais Ra (inicial e final) dos 6 grupos avaliados.

De acordo com a análise de variância foi observada diferença estatística entre as resinas acrílicas, sendo que a resina acrílica Duralay apresentou menor rugosidade de superfície. Também foi observada diferença estatística entre os tempos utilizados, demonstrando que as resinas acrílicas aumentaram a rugosidade superficial após a imersão nas soluções. Não houve diferença significativa entre as soluções utilizadas.

Tabela 1 - Análise de Variância do teste de rugosidade das resinas acrílicas, colutórios e tempos utilizados

\begin{tabular}{l|c|c|c|c}
\hline Fonte de Variação & G.L. & \multicolumn{2}{c}{ Quadrado Médio } & F \\
\hline Colutório (C) & 2 & 0,0125 & 0,66 & $47,23 \mathrm{~ns}$ \\
Resina acrílica (R) & 1 & 0,1890 & 9,94 & 0,33 * \\
Interação C x R & 2 & 0,0811 & 4,26 & 2,01 * \\
Resíduo I & 42 & 0,0190 & --- & -- \\
Tempos (T) & 1 & 0,1683 & 47,27 & 0,0003 * \\
Interação T x C & 2 & 0,0014 & 0,39 & $31,70 \mathrm{~ns}$ \\
Interação T x R & 1 & 0,0001 & 0,02 & $11,16 \mathrm{~ns}$ \\
Interação T x C x R & 2 & 0,0006 & 0,16 & $14,34 \mathrm{~ns}$ \\
Resíduo II & 42 & 0,0036 & --- & --- \\
\hline Total & 95 & --- & --- & -- \\
\hline
\end{tabular}

* Significante ao nível de $5 \%(p<0,05)$; ns - Não significante; Tukey $5 \%=0,103$.

Tabela 2 - Médias das rugosidades de superfície (Ra) dos grupos

\begin{tabular}{|c|c|c|c|c|}
\hline \multirow{3}{*}{ Imersão } & \multicolumn{4}{|c|}{ Resinas acrílicas } \\
\hline & \multicolumn{2}{|l|}{ Duralay } & \multicolumn{2}{|l|}{ Dencrilay } \\
\hline & Inicial & Final & Inicial & Final \\
\hline Soro fisiológico & $0,25^{a, b, c, d}$ & $0,34^{d, e, f}$ & $0,33^{a, b, c}$ & $0,31^{b, c, d, e}$ \\
\hline Periogard & $0,21 \mathrm{a}, \mathrm{b}$ & $0,28^{a, b, c, d, e}$ & $0,36^{e, f}$ & $0,43^{f}$ \\
\hline Listerine & $0,20^{a}$ & $0,28^{a, b, c, d, e}$ & $0,33^{\mathrm{c}, \mathrm{d}, \mathrm{e}, \mathrm{f}}$ & $0,43^{f}$ \\
\hline
\end{tabular}

Letras diferentes apresentam diferença estatística $(p<0,05)$ tanto nas linhas como nas colunas.

\section{Dıscussão}

A hipótese testada que as resinas acrílicas apresentam rugosidades de superfície diferentes e que os enxaguatórios bucais terão diferentes efeitos sobre a rugosidade das resinas acrílicas foi confirmada em parte.
As resinas acrílicas polimerizadas quimicamente são os materiais mais utilizados para a confecção de provisórios em prótese fixa e é clara a importância de um bom acabamento e polimento para menor acúmulo 
de placa e manutenção da saúde periodontal nas fases prévias a cimentação da restauração "definitiva". Além de menor rugosidade de superfície inicial, a manutenção dessa rugosidade é primordial durante todo o tratamento, mesmo quando submetido a meios adversos, como contato com produtos metabólicos de alimentos ou bochechos com enxaguatórios bucais. A rugosidade pode ser medida e expressa numericamente por diversos parâmetros, sendo o mais utilizado é a o escala Ra. Neste trabalho a influência dos enxaguatórios bucais sobre a rugosidade de superfície da resina acrílica foi avaliada por meio de rugosímetro e verificou-se que além do efeito do enxaguatório, o tipo de resina acrílica é um fator importante a ser analisado quando se busca lisura neste material.

De acordo com o trabalho de Bollen et al. ${ }^{1}$, uma rugosidade Ra superior a $0,2 \mu \mathrm{m}$ seria um limiar para a retenção de placa bacteriana, e sempre que este valor é aumentado, maior probabilidade de acúmulo de placa é esperado. Assim, os resultados deste estudo apresentaram valores médios superiores a $0,2 \mu \mathrm{m}$ sugeridos por esses autores $(0,2$ a $0,43 \mu \mathrm{m})$. Esses achados podem ter sido devido ao tipo de acabamento que foi dado na resina acrílica, pois foi utilizado apenas lixas d'água, sendo a mais fina com granulação 1200. As técnicas de polimento laboratorial nem sempre são padronizadas e uma superfície considerada lisa virtualmente pode ser micro-retentiva e favorecer a colonização de placa bacteriana ${ }^{15}$. Comparando diversos tipos de polimento, o estudo feito por Braun et al. ${ }^{3}$ mostrou que a resina acrílica Duralay apresenta melhor lisura quando comparada com as resinas acrílicas Denkor e Vipi Cor, caracterizando, como no presente estudo, que as resinas acrílicas apresentam rugosidade de superfície diferente mesmo sob um polimento similar.
Outro aspecto observado neste estudo foi que as resinas acrílicas aumentaram a rugosidade superficial após a imersão nas soluções para bochecho. Não foi encontrado trabalho específico avaliando a rugosidade de superfície de resinas acrílicas quando submersas nestes tipos de enxaguatórios que foram testados. Porém Lima et al. ${ }^{8}$ já verificaram que a rugosidade de superfície da resina acrílica aumentou após a permanência dos corpos-de-prova na cavidade bucal quando foi avaliado o efeito de alguns agentes de limpeza (Ortoform - Perborato de sódio e Enzima proteolítica e Hipoclorito de Sódio a $0,5 \%$ ).

Tem sido observado que a rugosidade da resina acrílica pode ser influenciada por diversos outros fatores além do tipo de resina e meios de imersão, como meios de polimerização e tipos de polimento realizado, conforme verificado por Schimidt et al. ${ }^{14} \mathrm{e}$ Cogo et al. ${ }^{6}$, tornado essa propriedade sujeita a grande variação de fatores.

Podemos salientar que de acordo com a literatura e os resultados obtidos, observa-se que ainda há poucos estudos para esclarecer de forma conclusiva sobre o real efeito dos enxaguatórios bucais na rugosidade das resinas acrílicas. Portanto, este trabalho também sugere que mais pesquisas devam ser realizadas, alternando as marcas comerciais, as técnicas de polimentos e inclusive os tipo de enxaguatórios bucais em diferentes tempos de imersão.

\section{Conclusão}

As soluções aumentaram a rugosidade de superfície das resinas acrílicas. Houve diferença de rugosidade entre as resinas acrílicas, entretanto, não houve diferença no aumento da rugosidade entre as soluções testadas. 


\begin{abstract}
The aim of this study was to evaluate the effect of two oral mouth rinses (Periogard [PER] Periogard [PER] (ColgatePalmolive Ind. Com. Ltda - São Paulo, SP, Brazil) and Listerine [LIS] (Johnson \& Johnson Healthcare Products - Skillman, NJ, USA)) in superficial roughness of two self-curing acrylic resins (Duralay [DUR] (Reliance Dental Worth, IL, USA] and Dencrilay [DEN] (Dencril Caieiras, SP, Brazil)). Physiologic solution [SOR] was used in control group. The research has a total of 06 groups $(n=08)$. For the confection of the testing samples, 48 molds were made of poliacetal with a cylindrical central hole with $5 \mathrm{~mm}$ of diameter and $5 \mathrm{~mm}$ of thickness. Therefore, with the mold positioned on a glass blade, acrylic resin was manipulated and inserted in the hole with a plastic syringe. With another blade, a compression force was realized against the mold and these things together were put in a pressure pot with water during the polymerization. Testing sample's faces were planned with sandpapers granulation 220 and the less irregular face was polished with others sandpapers $(320,400,600,1200)$ under refrigeration in a politrix. After 24 hours in water, initial reading was recorded with a roughness meter with Ra scale. The resin samples were immersed in the mouth rinses during $10 \mathrm{~min}$ /day for 10 days. Resins were stored in physiologic solution, between immersion intervals in mouth rinses. Control groups were all the time stored in physiologic solution. After this period, the resin samples were submitted to a new reading of roughness $(\mathrm{Ra})$, by the same evaluator. Initial results were: $\mathrm{DUR}+\mathrm{LIS}=0,20$; $\mathrm{DUR}+\mathrm{PER}=0,21$; $\mathrm{DUR}+\mathrm{SOR}=0,25 ; \mathrm{DEN}+\mathrm{LIS}=0,33 ; \mathrm{DEN}+\mathrm{SOR}=0,33 ; \mathrm{DEN}+\mathrm{PER}=0,36 ;$ and final: $\mathrm{DUR}+\mathrm{PER}=0,28 ; \mathrm{DUR}+\mathrm{LIS}=0,28$; $\mathrm{DEN}+\mathrm{SOR}=0,31 ; \mathrm{DUR}+\mathrm{SOR}=0,34 ; \mathrm{DEN}+\mathrm{PER}=0,43 ; \mathrm{DEN}+\mathrm{LIS}=0,43$. After Variance analysis and Tukey test $(5 \%)$, it was shown that acrylic resin Duralay presented less superficial roughness and mouth rinses increased their roughness. However, there were no differences among tested solutions.
\end{abstract}

\title{
UNITERMS
}

Acrylic resins; anti-bacterial agents; roughness.

\section{REFERÊNCIAS}

1. Bollen CM, Lambrechts P, Quirynen M. Comparison of surface roughness of oral hard materials to the threshold surface roughness for bacterial plaque retention: a review of the literature. Dent Mater 1997;13(4):258-69.

2. Borchers L, Tavassol F, Tschernitschek H. Surface quality achieved by polishing and by varnishing of temporary crown and fixed partial denture resins. J Prosthet Dent 1999;82(5):550-6.

3. Braun KO, Pellegrin DZ, Coradini L, May LG. Análise da rugosidade superficial de resinas acrílicas para coroas provisórias submetidas a diferentes tipos de polimento. Rev. Faculdade de Odontologia Universidade Passo Fundo 2006;11(2):41-44.

4. Brecx M, Brownstone E, MacDonald L, Gelskey S, Cheang M. Efficacy of Listerine, Meridol and Chlorhexidine mothrinses as supplements to regular tooth cleaning measures. J Clin Periodontol 1992;19(3):207-7.

5. Brecx M, Netuscheil L, Reichert B, Schreil G. Efficacy of Listerine, Meridol and Chlorhexidine mothrinses on plaque gingivitis and plaque bacteria vitality. J Clin Periodontol 1990;17(5):292-7.

6. Cogo DM, Cremonese RV, Rangel SM, Samuel SMW. Efeito de técnicas alternativas de polimento sobre a rugosidade superficial de resinas acrílicas. Rev Odontol Porto Alegre 2003;44(1):26-30.

7. Egelberg J. Fatos atuais sobre a terapia periodontal. Rio de Janeiro: $\mathrm{P} \& \mathrm{R}, ; 2002$.

8. Lima EMCX, Moura JS, Del Bel Cury AA, Garcia RCMR, Cury JA. Effect of enzymatic and $\mathrm{NaOCl}$ treatments on acrylic roughness and on biofilm accumulation. J Rehabilitation 2006;(33):356-62.

9. Lindhe J. Tratado de periodontia clínica e implantodontia oral. 3.ed. Rio de Janeiro: Guanabara e Koogan; 1999.

10. Maruniak J. et al. The effect of 3 mouthrinses on plaque and gingivitis development. J Clin Periodontol 1992;19:19-23.
11. Nepplelenbroek KH, Pavarina AC, Vergani CE, Giampaolo ET. Hardness of heart-polymerized acrylic resins after disinfection and longterm water immersion. J Prosthet Dent 2005;(93):171-6.

12. Nikawa H, Hamada T, Yamamoto T. Denture plaque-past and recent concerns. J Dent 1998;26(4):299-304.

13. Quirynen M, Bollen CML. The influence of surface roughness and surface free energy on supra and sub gengival plaque formation in man. A review of the literature. J Clin Periodontol 1995;22:1-14.

14. Schmidt CB, Sartori EA, Maccari PCA, Shinkai RSA. Rugosidade superficial de resina acrílica submetida a diferentes métodos de polimento. Rev Odonto Ciência 2004;19(44):117-21.

15. Taylor R, Maryan C, Verran J. Retention of oral microorganisms on cobalt-chromium alloy and dental acrylic resin with different surface finishes. J Prosthet Dent 1998,80(5)592-97.

16. Torres CRG, Kubo CH, Anido AA, Rodrigues JR. Agentes antimicrobianos e seu potencial uso na Odontologia. Pós-Grad Rev Fac Odontol São José dos Campos 2000; 3(2):43-52

Recebido em 25/03/2009

Aprovado em 05/10/2009

Correspondência André Mallmann

Endereço: Rua Venâncio Aires, 1795 / sala 71. Santa Maria - RS CEP: 97010-003 e-mail: andremallmann@uol.com.br 